\title{
A Comparative Study of the Effect of Cellulose-based Deep Coating and Pulp Refining on the Structural and Mechanical Properties of Paper
}

\author{
Marta Krysztof, ${ }^{a}$ Konrad Olejnik, ${ }^{\mathrm{a}, *}$ Piotr Kulpiński, ${ }^{\mathrm{b}}$ Aleksandra Erdman, ${ }^{\mathrm{a}}$ and \\ Elżbieta Sąsiadek ${ }^{\mathrm{b}}$
}

\begin{abstract}
A new coating method was developed, based on cellulose regenerated from an $\mathrm{N}$-methylmorpholine $\mathrm{N}$-oxide (NMMO) solution applied to paper. In particular, the purpose of this study was to compare the effectiveness of the "deep coating" method using cellulose regenerated from NMMO solution and the classic pulp refining process as methods to improve paper mechanical properties and overall quality. The "deep coating" name comes from the fact that the coating process is combined with subsequent heating of the coating before its final solidification. As a result of this operation, deep penetration of the cellulosic solution into the paper structure occurs. This increases the contact surface of the solution with the cellulosic fibers, which increases the strength properties of the paper structure. It was found that the cellulosic coating increased the apparent density of the paper, the tensile strength, the elongation, the resistance to bursting, and the double fold number. However, the coating also decreased the air permeability and the tear resistance of the paper samples. Despite some technological difficulties, this method could be an attractive solution in the case of a need for additional functionalization of a paper structure.
\end{abstract}

Keywords: Paper coating, deep coating; Regenerated cellulose; N-Methylmorpholine N-oxide; NMMO; Cellulosic coating; Strength improvement; Structure modification; Pulp refining

Contact information: a: Centre of Papermaking and Printing, Lodz University of Technology, Wólczanska 223, 90-924 Lodz, Poland; b: Department of Mechanical Engineering, Informatics and Chemistry of

Polymer Materials, Lodz University of Technology, Żeromskiego 116, 90-924 Lodz, Poland;

*Corresponding author: konrad.olejnik@p.lodz.pl

\section{INTRODUCTION}

The main purpose of the coating process in paper technology is the functional modification of the material surface. The most frequently expected results are related to the improvement of the printing properties, such as the smoothness, whiteness, gloss, opacity, or barrier properties (Tracton 2007; Holik 2013; Tyagi et al. 2019; Nechita and Roman 2020). Classic coating compounds usually contain an inorganic pigment (e.g. titanium dioxide $\left(\mathrm{TiO}_{2}\right)$, calcium carbonate $\left(\mathrm{CaCO}_{3}\right)$, and kaolin), a binder (e.g. polyvinyl alcohol, styrene butadiene latexes, acrylic acid, carboxymethyl cellulose, starch), and auxiliary substances. The most important auxiliary substances include dispersing agents, optical brighteners, $\mathrm{pH}$ stabilizers, viscosity stabilizers, substances modifying the coefficient of friction of the paper surface, defoamers, and biocides (Tracton 2007; Holik 2013). Coatings can also be used to improve the strength properties of the paper surface, mainly the dry pick resistance. There are also reports in the scientific literature describing the possibilities of improving the strength properties of the entire material by coating 
operation. However, coating is usually less effective because the dry strength agent remains mainly on the surface of the material. As a result, the impact of coating on the whole structure of the paper is very limited. Moreover, agents used for this purpose are often based on synthetic polymers (Morsy and El-Sherbiny 2004) or substances of limited availability (Balan et al. 2015). For effective improvement of the mechanical properties of the paper, dry strength additives must be dispersed evenly in the volume of the papermaking pulp. As a result, polymer macromolecules will have the potential to be concentrated around contacting fibers and parts of direct fiber-fiber bondings are replaced by fiber-polymer-fiber bondings (Rathi and Biermann 2000; Lindström et al. 2005; Lofton et al. 2005; Holik 2006; Jenkins 2009; Mihara et al. 2018).

The growing demand for biodegradable and environmentally friendly materials has resulted in a rapid growth of interest in cellulose-based nanomaterials (NC). There are many reports related to the application of these materials also for paper modification including as a coating agent (Hubbe et al. 2017; Samyn et al. 2018; Tyagi et al. 2019). Despite the numerous advantages of cellulosic nanomaterials, there is still an opinion that the research and application of NC as a nano-coating agent is still in its infancy (Li et al. 2021). On the other hand, it is surprising that so far there are only few reports on the use of another form of this compound in papermaking: cellulose regenerated from the solvent solutions. Research carried out by Krysztof et al. (2018) showed that the coating based on cellulose regenerated from an $N$-methylmorpholine $N$-oxide (NMMO) solution applied to paper had a significant impact on the paper structure and its mechanical properties. These studies also show that depending on the further handling of this coating after its application (i.e. heating prior to final solidification or the immediate solidification by NMMO washing), different paper structures and different mechanical properties can be obtained. Of particular interest from the point of view of improving strength properties is the "deep coating" method. The "deep coating" method combines the coating process with subsequent heating of the coating before its final solidification. Because the melting point of the cellulose solution in NMMO is above $70{ }^{\circ} \mathrm{C}$, the heating of the coated paper prior to removing NMMO results in deep penetration of the coating solution into the paper structure. During solvent rinsing, regenerated cellulose precipitates not only on the surface of the paper but also inside it. The increase in paper strength is probably due to the fact that the precipitated cellulose partially fills the pores between the fibers and supports the bonding of the fibers. The research on "deep coating" carried out so far concerned only papers made from unrefined pulp. It seems, that the use of an NMMO regenerated cellulose coating may have additional advantages. Numerous publications (Rubacha 2006; Kulpiński 2007; Śmiechowicz et al. 2018; Skwierczyńska et al. 2019) found that cellulose solutions in NMMO can be quite easily modified by introducing various additives. The additives can be both inorganic and organic compounds, which are added to the cellulose solution in NMMO in the form of dispersion in a polar liquid. This method can create cellulose fibers with unique properties, such as electrically conductive, luminescent, and antibacterial properties, among others. Research by Erdman et al. (2016) showed that cellulose fibers functionalized in this way are very resistant to mechanical impacts and aging factors. It was found that even in the case of mechanical damage of the fiber structure, the substance used for its functionalization remained in the structure and did not release into the environment. Based on completed but unpublished studies, it was found that the modified fibers' resistance to aging is over 10 years. It can be expected that a coating made of cellulose regenerated from NMMO solution will have similar durability.

The purpose of the present study was to investigate the effect of the paper coating 
by the cellulose-NMMO solution and to compare the effectiveness of the "deep coating" method using cellulose regenerated from NMMO solution and the classic pulp refining process as methods to improve paper properties and overall quality. This work describes the impact of both methods on the structural and strength properties of paper.

\section{EXPERIMENTAL}

Commercial bleached softwood kraft pine pulp (BSK), obtained from one of the Polish paper mills, was used to prepare the laboratory handsheets. The pulp parameters are presented in Table 1.

Table 1. Initial Parameters of the BSK Pine Pulp Used for the Laboratory Handsheet Preparation

\begin{tabular}{|c|c|}
\hline Initial moisture content & $6.22 \%$ \\
\hline Degree of polymerization (DP) & 1081 \\
\hline$\alpha$-cellulose content & $86.6 \%$ \\
\hline Schopper-Riegler (SR) value & SR-12 \\
\hline
\end{tabular}

The pulp samples were prepared according to the ISO standard 5263-1 (2004). The pulp refining was carried out in a PFI mill according to the TAPPI T 248 sp-00 (2000) standard method. The refining conditions that were used in the research are presented in Table 2. The drainability of the refined pulps was tested in accordance with the ISO standard 5267-1 (1999) via the Schopper-Riegler method.

Table 2. PFI Refining Conditions and Corresponding SR values of the Refined BSK Pine Pulp

\begin{tabular}{|c|c|}
\hline No. of PFI Revolutions & SR Value ('SR) \\
\hline 0 & 13 \\
\hline 1500 & 15 \\
\hline 2500 & 22 \\
\hline 4500 & 36 \\
\hline 6000 & 45 \\
\hline 9000 & 55 \\
\hline
\end{tabular}

The $70 \mathrm{~g} / \mathrm{m}^{2}$ laboratory handsheets were formed in a Rapid-Köthen apparatus according to the ISO standard 5269-2 (2005). The obtained laboratory sheets were used as a base paper for a subsequent coating. According to previous research by Krysztof et al. (2018), bleached beech kraft pulp was used to prepare a cellulosic solution of coating agent. The pulp parameters are presented in Table 3.

Table 3. Parameters of BSK Beech Pulp Used for Coating Agent Preparation

\begin{tabular}{|c|c|}
\hline Initial moisture content & $5.25 \%$ \\
\hline Degree of polymerization (DP) & 655 \\
\hline$\alpha$-Cellulose content & $92.3 \%$ \\
\hline
\end{tabular}

The cellulose solution was obtained in a high-efficiency laboratory-scale IKA VISC kneader (MKD 0.6-H60, Staufen, Germany). A 50/50 water and NMMO solution 
was mixed with the appropriate amount of BSK beech pulp so that after the excess water was removed, the solution had a $3 \%$ of $\alpha$-cellulose content. The mixture was heated at a temperature of $95{ }^{\circ} \mathrm{C}$ under low pressure (approximately $6.7 \mathrm{kPa}$ ), and the excess water was removed from the system. The process continued until a homogeneous and transparent cellulose solution in the NMMO was obtained. The duration of this process was approximately 3 hours. The solution prepared in this way remains solid at room temperature. Before the coating process, the cellulose solution was melted and kept at a temperature of $80 \pm 2{ }^{\circ} \mathrm{C}$. The application of the cellulose-NMMO solution to a paper surface was carried out with the use of an automatic coater (Control Coater; IPP/TUL, Lodz, Poland), at a speed of $16 \mathrm{~cm} / \mathrm{s}$ and with the use of a standard Mayer rod No. 3 (Kbar) which gave wet film thickness of $24 \mu \mathrm{m}$ (dry coating thickness of approximately 0.8 $\mu \mathrm{m})$.

To allow the migration of the coating solution onto the paper structure, the coated papers were kept at a temperature of $80 \pm 2{ }^{\circ} \mathrm{C}$ in a KBC-32 drier (WAMED, Warsaw, Poland) for $10 \mathrm{~min}$. According to the method used by Krysztof et al. (2018), the final solidification of the coating was achieved as a result of the NMMO removal from the cellulose coating and drying the coated papers. The NMMO removal was carried out by immersing a sample of coated paper in a water bath at a temperature of $37 \pm 2{ }^{\circ} \mathrm{C}$ for 120 s. This coating method is known as "deep coating."

All paper samples were conditioned according to the ISO standard 187 (1999). All properties were determined in accordance with relevant ISO standards listed in Table 4.

Table 4. The ISO Testing Standards for the Paper Samples

\begin{tabular}{|c|c|}
\hline Tested Property & ISO Standard \\
\hline Grammage & ISO 536 (2019) \\
\hline Thickness and apparent density & ISO 534 (2011) \\
\hline Tensile index and elongation & ISO 1924-2(2008) \\
\hline Elmendorf tear resistance & ISO 1974 (2012) \\
\hline Bendtsen surface roughness & ISO 8791-2(2013) \\
\hline Bendtsen air permeance & ISO 5636-3 (2013) \\
\hline Folding endurance (Schopper device) & ISO 5626 (1993) \\
\hline Bursting strength & ISO 2758(2014) \\
\hline
\end{tabular}

The paper surface properties were observed via a VEGA3 SBU scanning electron microscope (SEM) (Tescan, Brno, Czech Republic). The samples for the SEM examination were gold and palladium coated using an SC7620 Mini Sputter Coater/Glow Discharge System (Quorum Technologies, Laughton, United Kingdom).

\section{RESULTS AND DISCUSSION}

\section{Structural Properties of the Paper Samples}

Based on the results obtained in the studies described by Krysztof et al. (2018) for comparison, a coating method combined with heating for $10 \mathrm{~min}$ was selected as the method that obtained the best improvement in the mechanical properties of the paper. As previously shown, further heating of the coating layer resulted in the cellulose solution penetrating deep into the paper structure. Therefore, the interaction of the coating solution was not limited to the surface of the material. 
In the present research, a cellulose coating was applied to paper samples made from pulp with different degrees of refining. The results of the coated paper properties were compared with the results obtained for the handsheets made from the same pulp, but without the coating. Figure 1 presents a comparison of the surface structure with regenerated cellulose coating located on the surface only (Fig. 1a) and paper coated using the "deep coating" method (Fig. 1b). Figure 1b shows that the regenerated cellulose penetrated deep into the structure of the paper and surrounded the fibers.
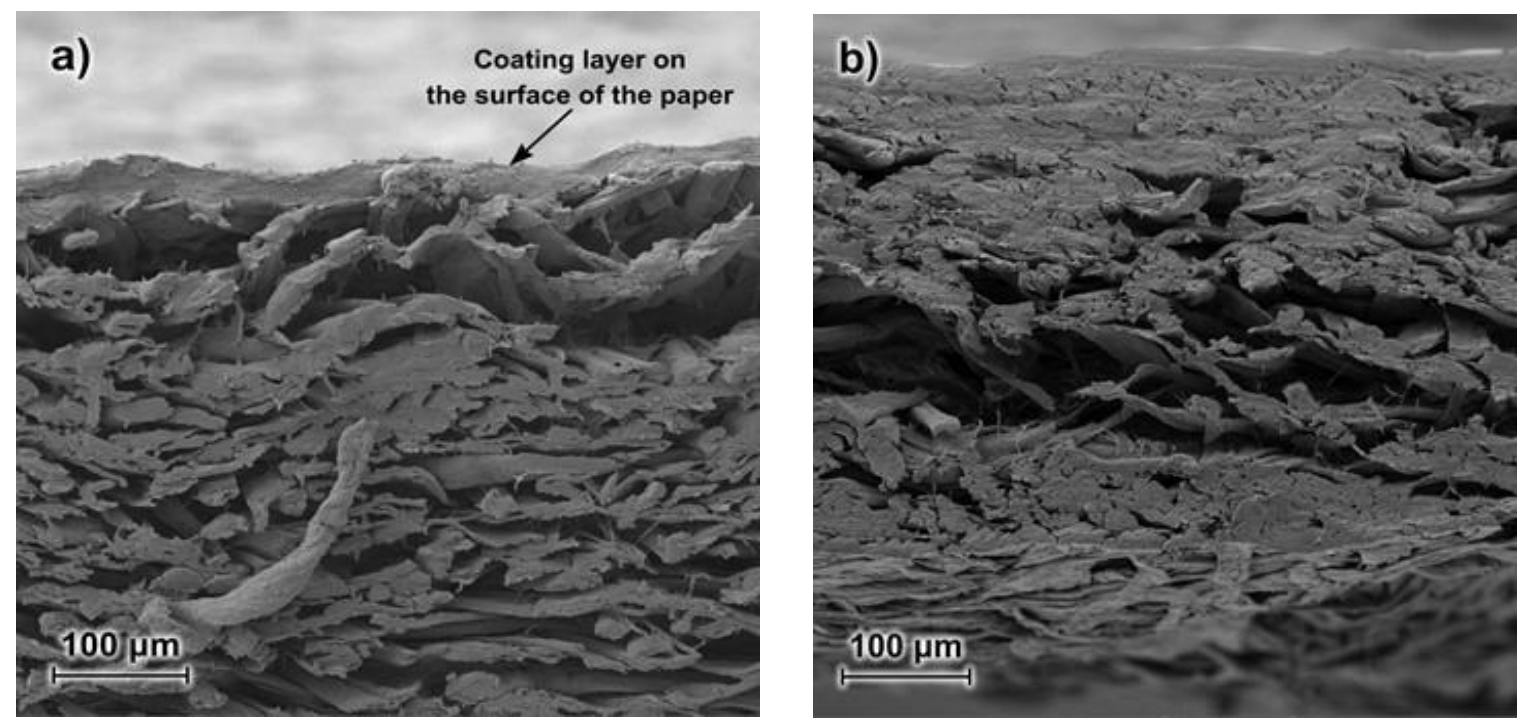

Fig. 1. Cross-section of the paper samples made from the unrefined pulp a) with the regenerated cellulose coating located on the surface only (mag. $\times 500)$ and b) with the regenerated cellulose applied using the "deep coating" method (mag. $\times 500$ ).

To show further differences between the conventional and "deep coating" methods, images of the surface of the paper coated with both methods are presented in Fig. 2.
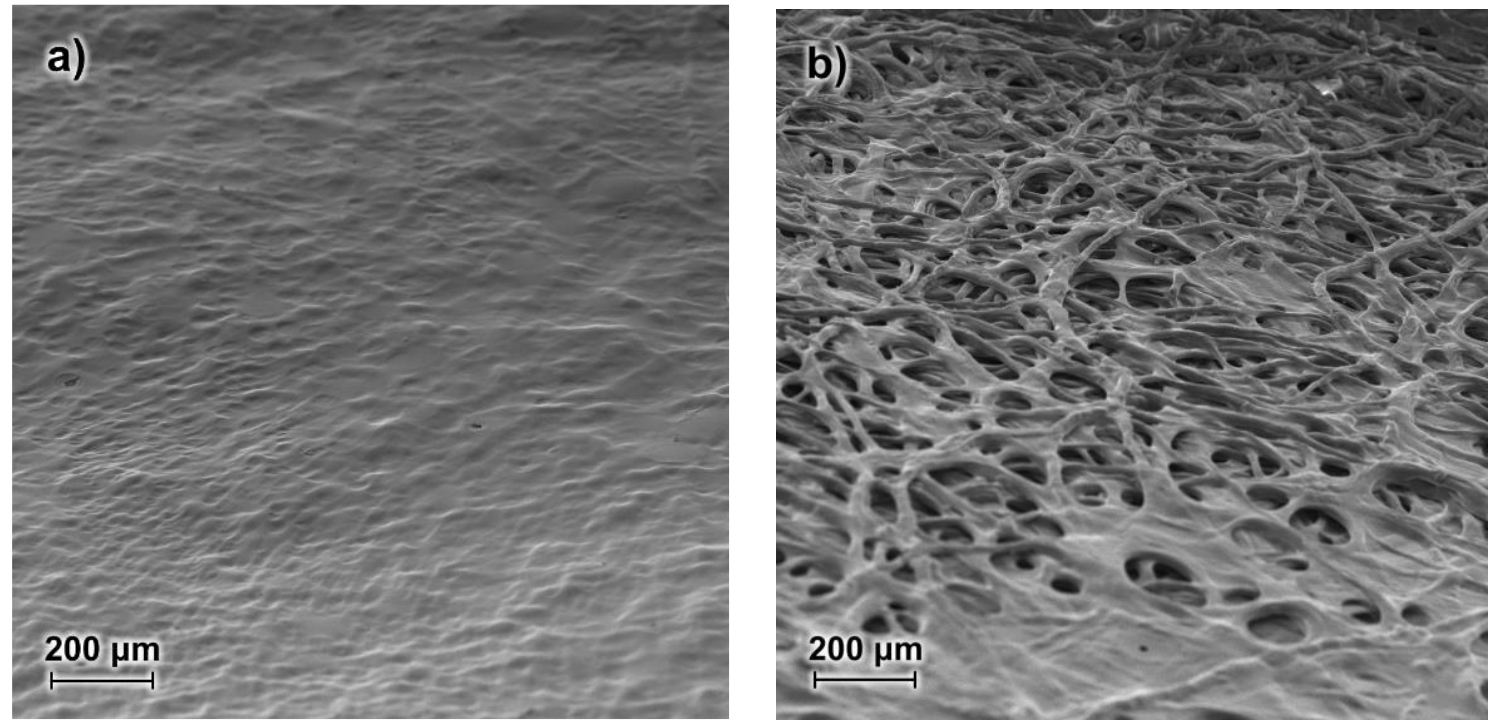

Fig. 2. Surface of the paper samples made from the unrefined pulp a) with the regenerated cellulose applied using the conventional method (mag. $\times 200)$ and b) with the regenerated cellulose applied using the "deep coating" method (mag. $\times 200$ ) 
The apparent density of paper is defined as the weight-to-thickness ratio of the tested paper, expressed in $\mathrm{g} / \mathrm{m}^{3}$. This value, similar to air permeability parameters, characterizes the compactness of the paper structure. The apparent density value is also related to the mechanical and optical properties of the paper, and it corresponds with the paper porosity and its ability to absorb liquids.

Figure 3 presents a comparison of the effect of the cellulose coating and the pulp refining process on the apparent density of the laboratory-made paper samples. The results showed that as the degree of refining increased, the apparent density of the paper also increased. This was due to the increased flexibility of the fibers as they were refined. As a result of the increased refining, the fibers became more closely adjacent to each other in the structure of the material. In addition, the fines that were generated during the refining process filled the pores between the fibers, which caused the paper structure to become less porous.

The application of the coating of the regenerated cellulose from the NMMO solution resulted in an additional, proportional increase in apparent density in comparison to the apparent density of the uncoated samples. The apparent density increased by approximately $0.063 \mathrm{~g} / \mathrm{cm}^{3}$. The smallest difference (approximately $0.055 \mathrm{~g} / \mathrm{cm}^{3}$ ) was observed for the paper samples made from the unrefined and lightly refined pulp (SR-13 and SR-15, respectively). The largest difference in the apparent density was observed for the paper samples made from the SR-45 pulp, which was equal to $0.083 \mathrm{~g} / \mathrm{cm}^{3}$. In general, the increase in the apparent density for coated paper samples ranged from approximately $8 \%$ to $12 \%$.

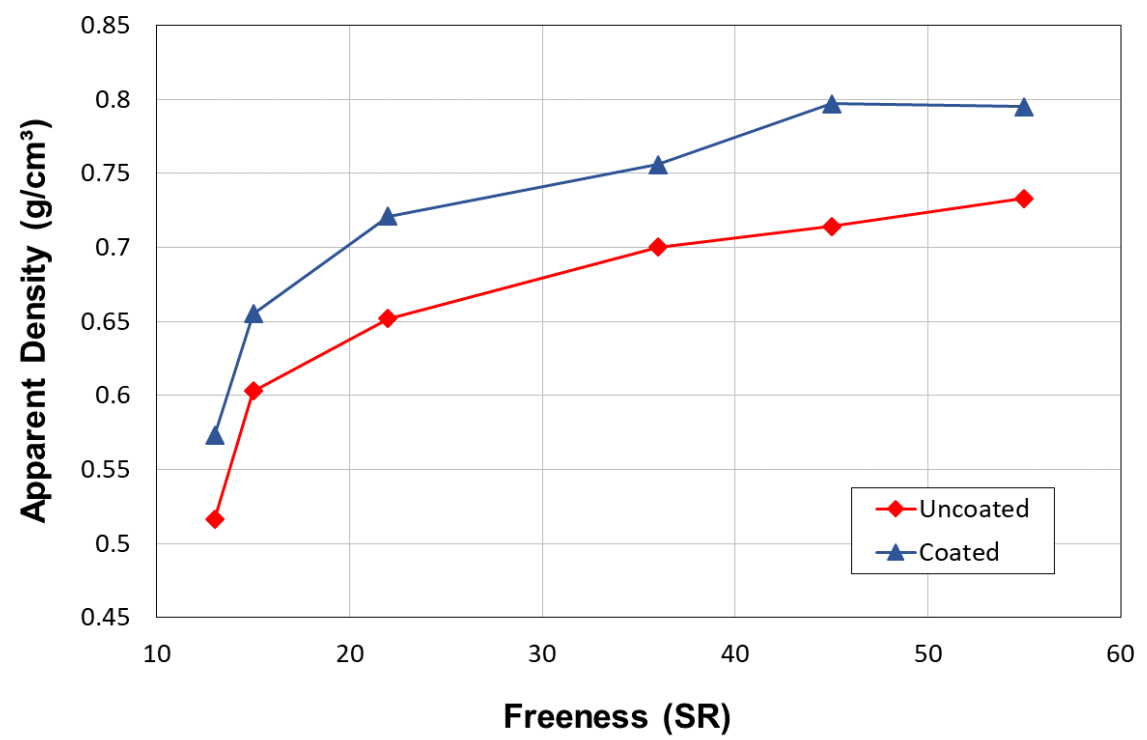

Fig. 3. Comparison of the apparent density of the handsheet samples made from the BSK pulp with different refining degrees for both the uncoated and coated handsheets with cellulose regenerated from the NMMO solution

The effect of the decrease in porosity of the paper structure can be confirmed by the air permeability parameter. The changes in the air permeability as a function of the apparent density are shown in Fig. 4. In the case of the uncoated paper samples made from the pulp refined to different SR values, a typical change characteristic was observed in this parameter. The paper that was made from the unrefined or lightly refined pulp (SR-13 and 
SR-15) had high air permeability values $(5,000 \mathrm{~mL} / \mathrm{min}$ and 4,800 $\mathrm{mL} / \mathrm{min}$, respectively). As the pulp refining degree increased, the air permeability decreased to $77 \mathrm{~mL} / \mathrm{min}$ for the SR-45 pulp and $36 \mathrm{~mL} / \mathrm{min}$ for the SR-55 pulp. The coated paper samples exhibited even lower air permeability values. The paper samples made from the unrefined cellulose (SR13) had an air permeability value of $4,980 \mathrm{~mL} / \mathrm{min}$. However, the air permeability of the paper samples made from the slightly refined pulp (SR-15) decreased to $324 \mathrm{~mL} / \mathrm{min}$, which was close to the value obtained for the uncoated paper made from the pulp refined to SR-36. For the paper samples made from the pulp refined to SR-55 that were coated with a cellulose solution, the air permeability decreased to $6 \mathrm{~mL} / \mathrm{min}$. These results indicated that the cellulose coating was the main factor that limited the air permeability. The effect of the apparent density of the paper was of secondary importance in this case.

To estimate the influence of the coating of regenerated cellulose from NMMO solution on the changes in the structure of the paper samples made from pulp with different refining degrees, the surface roughness of the uncoated and coated samples was compared. These results are shown in Fig. 5. For the uncoated paper samples, the roughness value decreased as the refining time increased. This was caused by the shortening of the cellulose fibers during the refining process, the formation of fines which filled the pores in the paper structure, and the general homogenization of the system. As the refining degree increased, the roughness of the paper samples decreased from approximately $600 \mathrm{~mL} / \mathrm{min}$ to 307 $\mathrm{mL} / \mathrm{min}$, which is in accordance with the generally known relationship. Additional applications of cellulose coating caused the influence of the refining process on the roughness of the paper surface to become practically negligible. In all cases, the surface of the samples with the cellulose coating was smoother and the roughness value changed modestly, decreasing with increasing degrees of pulp refining from 317 to $278 \mathrm{~mL} / \mathrm{min}$. In this case it could be pointed out that the coating of regenerated cellulose is more effective than intensive beating process.

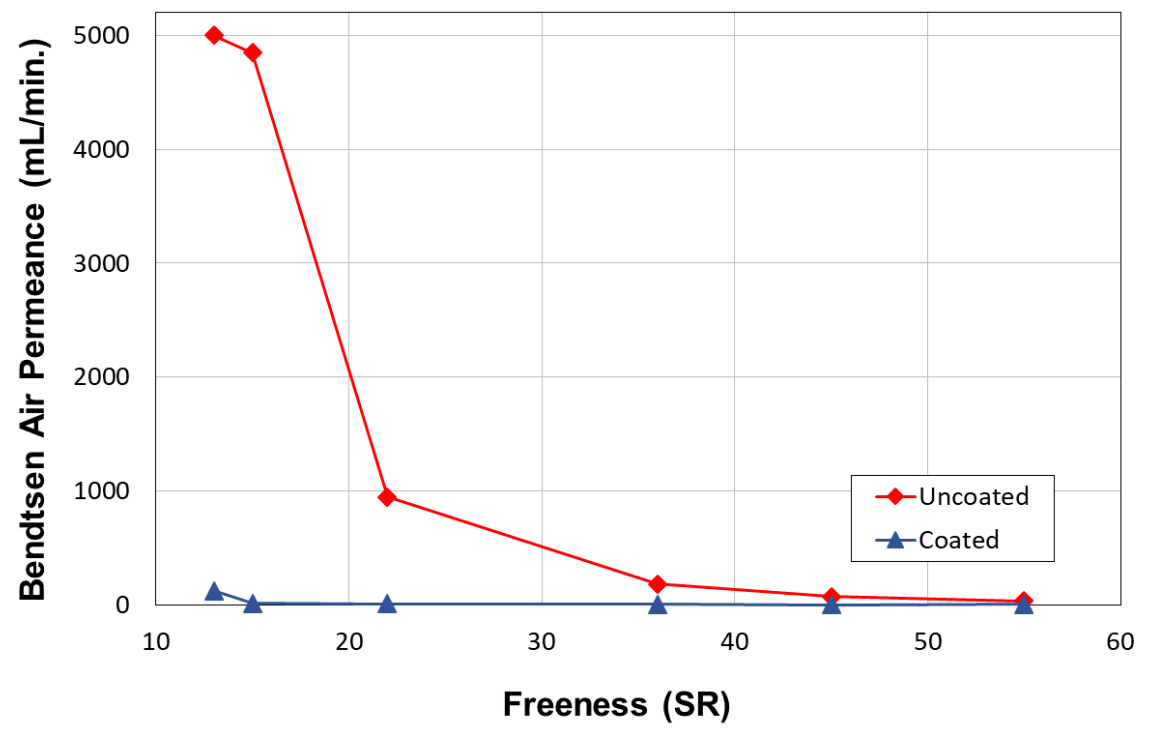

Fig. 4. Comparison of the air permeability for the handsheets made from the BSK pulp with different refining degrees for both the uncoated and coated handsheets with regenerated cellulose from NMMO solution as a function of their apparent densities 


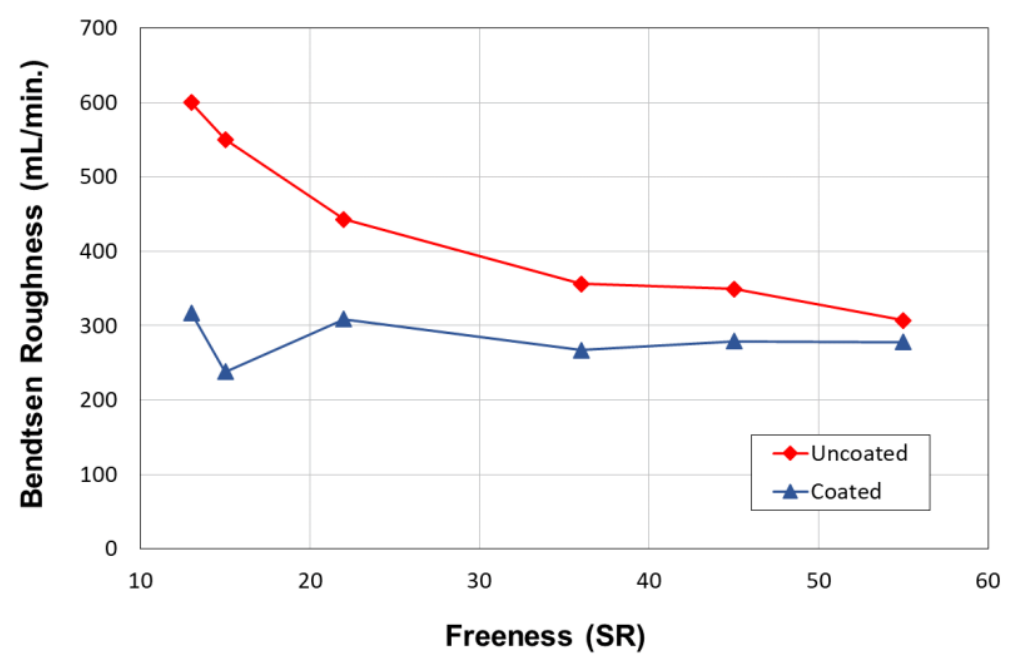

Fig. 5. Comparison of the roughness of the handsheets made from the BSK pulp with different refining degrees for both the uncoated and coated handsheets with cellulose regenerated from NMMO solution

\section{Strength Properties of the Paper Samples}

During use, paper materials can be subjected to various mechanical stresses. They can be stretched, compressed, torn, twisted, bent, or burst. Two mentioned parameters of paper are particularly important: the tensile strength and the tear resistance. It is widely known that modifications to pulp during the refining process cause paper made from such pulp to exhibit an increase in the tensile strength and, at the same time, a decrease in the tear resistance due to the shortening of the fibers.

To assess the papermaking ability of the pulp and the overall mechanical strength of paper, a diagram showing the tensile strength as a function of the tear resistance is often used (Fig. 6). This figure compares the relationship between the tear resistance index and the tensile index of the laboratory paper samples made from the BSK pulp refined to different SR values, which were uncoated and coated with cellulose regenerated from NMMO solution. The results indicated that in all cases, the coated paper samples had lower tear resistance index values. It was also observed that the presence of the cellulose coating improved the tensile strength, but only for the paper samples made from unrefined and modestly refined pulp (up to SR-22). For the samples that were made from refined pulp characterized by freeness values of SR-36 and SR-45, the tensile strength index values were equal for both the coated and uncoated papers. The clear advantage of the refining process (in terms of higher tensile strength values) was visible for the paper made from pulp refined to SR-45 and above. In this case, the tensile strength index for the uncoated paper was $105 \mathrm{~N} \cdot \mathrm{m} / \mathrm{g}$, whereas for the coated paper it was only $89 \mathrm{~N} \cdot \mathrm{m} / \mathrm{g}$.

In general, it was observed that for more porous surfaces and paper structures, the coating increased the strength properties. Therefore, it can be concluded that in such cases the coating solution can penetrate the paper structure more easily and deeply. As a result, cellulose coating can affect (bind) a larger area of fibers in the paper structure. As the degree of pulp refining increased, the porosity of the paper decreased (Figs. 3 and 4). In such cases, the cellulose solution probably did not penetrate deeply enough into the paper structure and its effect was limited only to the surface of the material. Similar effects are observed in the papermaking industry where cationic starch is used as a dry-strength additive. 


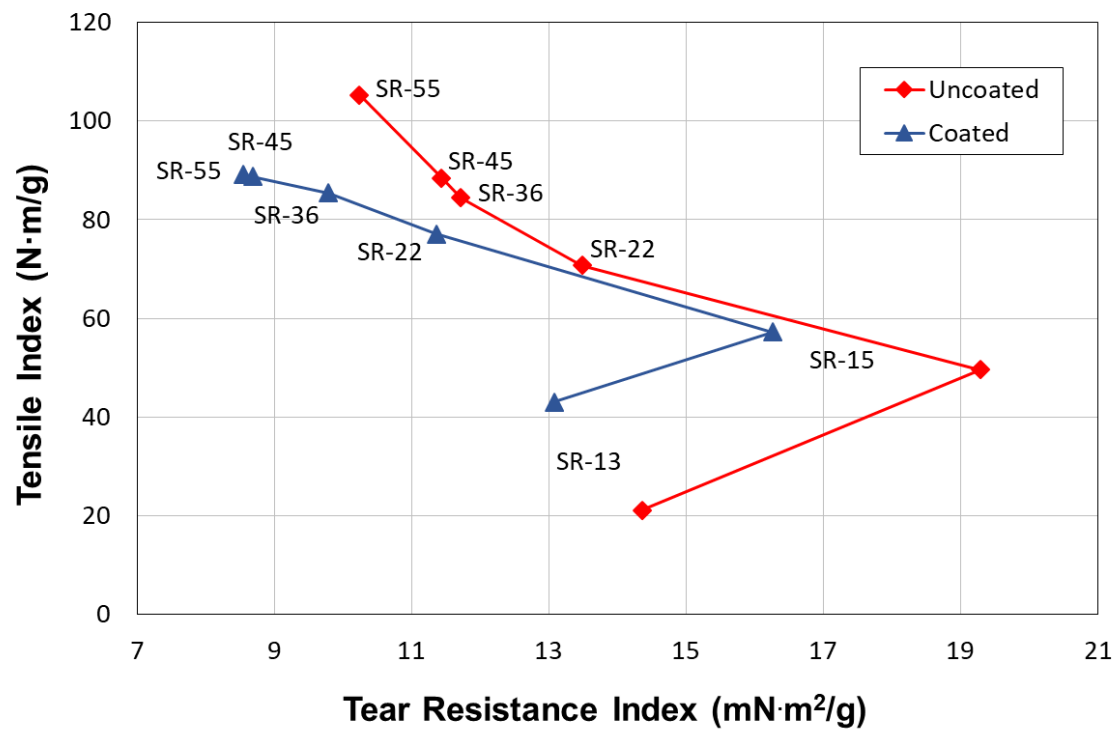

Fig. 6. Comparison of the tear resistance index vs. tensile index for the handsheets made from the BSK pulp with varying degrees of refining for both the uncoated and coated handsheets with cellulose regenerated from NMMO solution

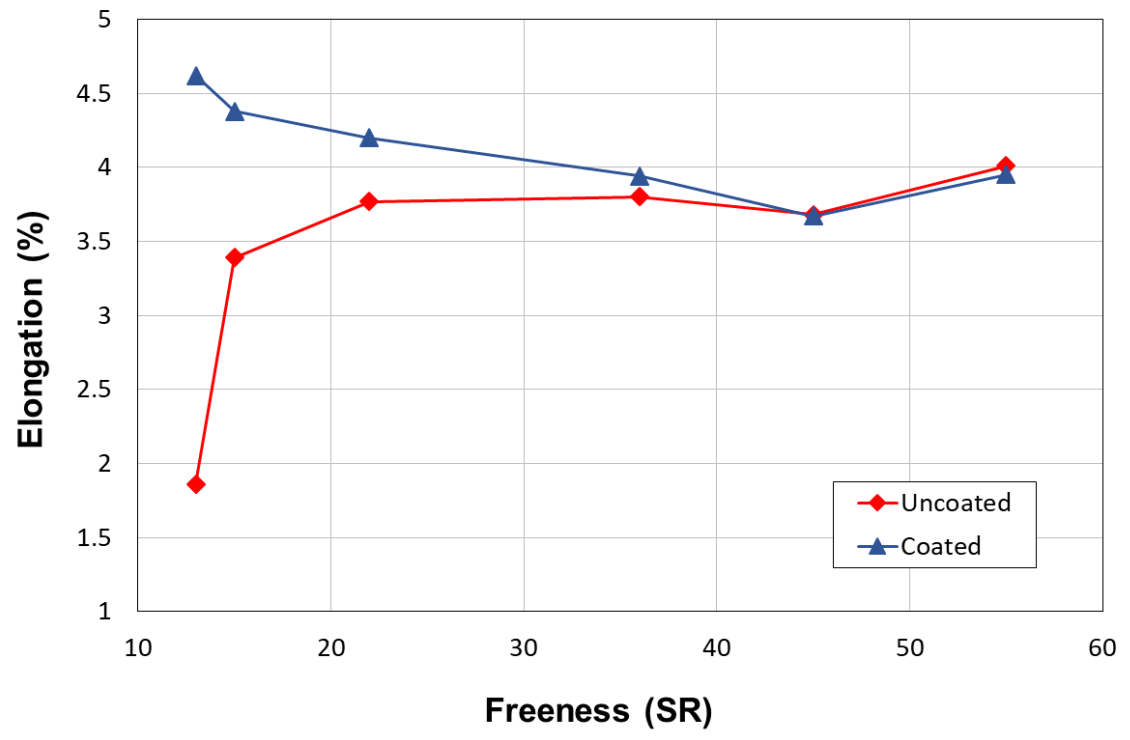

Fig. 7. Comparison of the elongation of the handsheets made from the BSK pulp with different refining degrees for both the uncoated and coated handsheets with cellulose regenerated from NMMO solution

To achieve a significant increase in paper strength, starch must be used to dose to the pulp volume. The surface application of starch improves the pick resistance (surface strength) but it does not significantly increase the strength properties of the paper. It should be also noted that while some improvement in the tensile strength was observed, the cellulose coating had an adverse effect on the tear resistance index. The tear index normally decreases when inter-fiber bonding increases beyond a certain point. Higher inter-fiber bonding renders the paper more brittle, so that it tends to fracture in a narrow region, thus not consuming very much energy during tearing. However, it can be assumed that observed 
effect was most likely due to the impact of the solvent (NMMO), which was in the coating solution on the cellulose fibers. It is known that during the extended heating process, this solution penetrates the paper structure. Therefore, the presence of NMMO probably causes a partial dissolution of cellulosic material (fibrils, exposed fragments of the cell wall of fibers) and thus additionally affects the structure of the whole material. A decrease in the tear resistance of the tested paper samples is the negative effect of these phenomena.

Figure 7 shows the effect of the coating application on the elongation of the tested paper samples. The application of the cellulose coating caused the elongation to increase up to a maximum value of $4.62 \%$ for the handsheets made of the unrefined pulp. The uncoated paper made from the unrefined pulp had the lowest elongation of $1.86 \%$. As the pulp was refining further, the elongation values of the uncoated paper increased, while the elongation values of the coated paper samples exhibited a decreased in relation to the maximum value obtained for the coated paper made of the unrefined pulp. For the pulp with freeness values of SR-45 and SR-55, the elongation values of the uncoated and coated paper were equal. The results indicated that the applied coating of regenerated cellulose from NMMO solution can effectively increase the paper elongation in a situation where it has a porous structure (e.g. it is made from unrefined pulp). Most likely, just as in the case of tensile strength, this means that the cellulose solution can penetrate deeply into its structure because the binding surface with cellulose fibers is much larger.

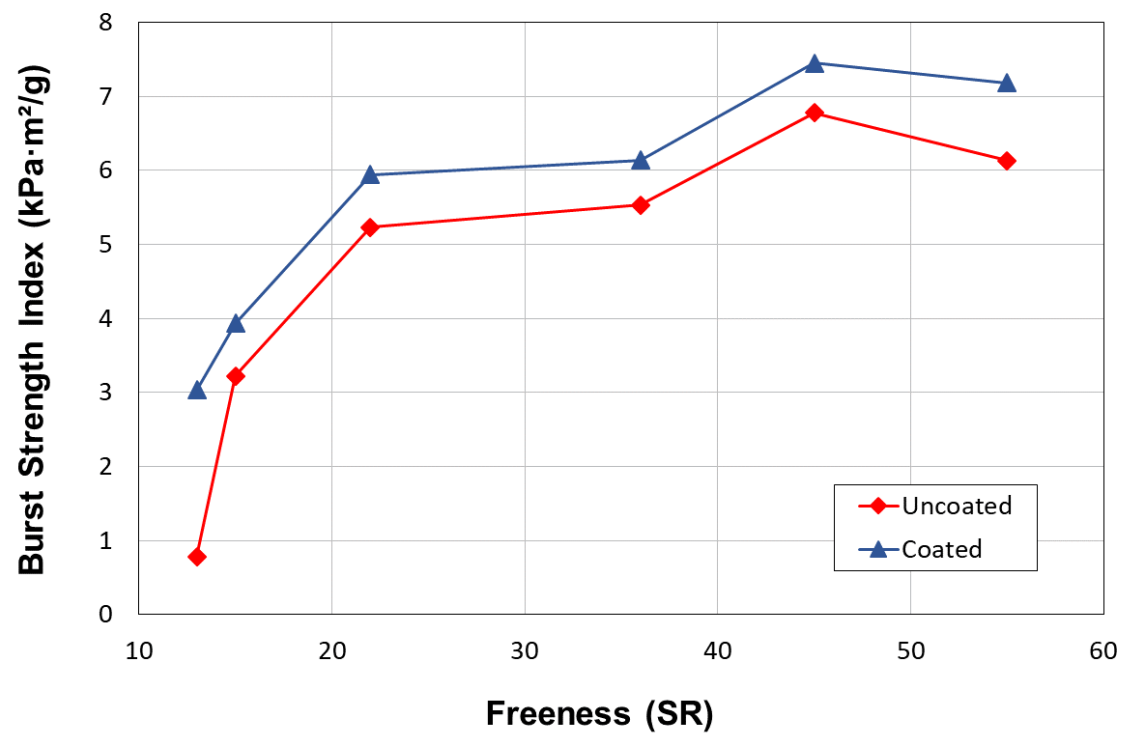

Fig. 8. Comparison of burst strength index for the handsheets made from the BSK pulp with varying refining degrees for both the uncoated and coated handsheets with cellulose regenerated from NMMO solution

Figure 8 shows changes in the burst strength index as a function of the freeness for the uncoated and coated paper samples. As the refining degree increased, the burst strength resistance of the uncoated paper samples increased. The application of the regenerated cellulose coating from the NMMO solution resulted in an additional, proportional increase in the burst strength in relation to the values obtained for the uncoated paper samples. Higher burst strength index values were noted for the refined pulp across various freeness levels.

The folding endurance was the last mechanical parameter to be tested (Fig. 9). It is 
widely known that the folding endurance increases as the degree of pulp refining increases. However, there is a limit of the refining process beyond which the folding endurance strength can decrease. The results from this study confirmed this rule. Among the uncoated paper samples, the highest double fold number (1133) was obtained for the samples that were made from the refined pulp with a freeness value of SR-22 value. The coated papers had higher double fold values when compared with the papers that were made from pulp of the same refining degree. Moreover, the lowest folding endurance value, obtained for coated paper, was still higher than the highest value measured for the uncoated paper samples. Starting from the SR-13 value (unrefined pulp), the double fold number for the coated paper was equal to 1228. The highest double fold number among the coated paper samples was obtained for the paper made of the pulp with a freeness of SR-22. This was equal to 1667. As the level of refining increased, the double fold number decreased for both the uncoated and coated papers.

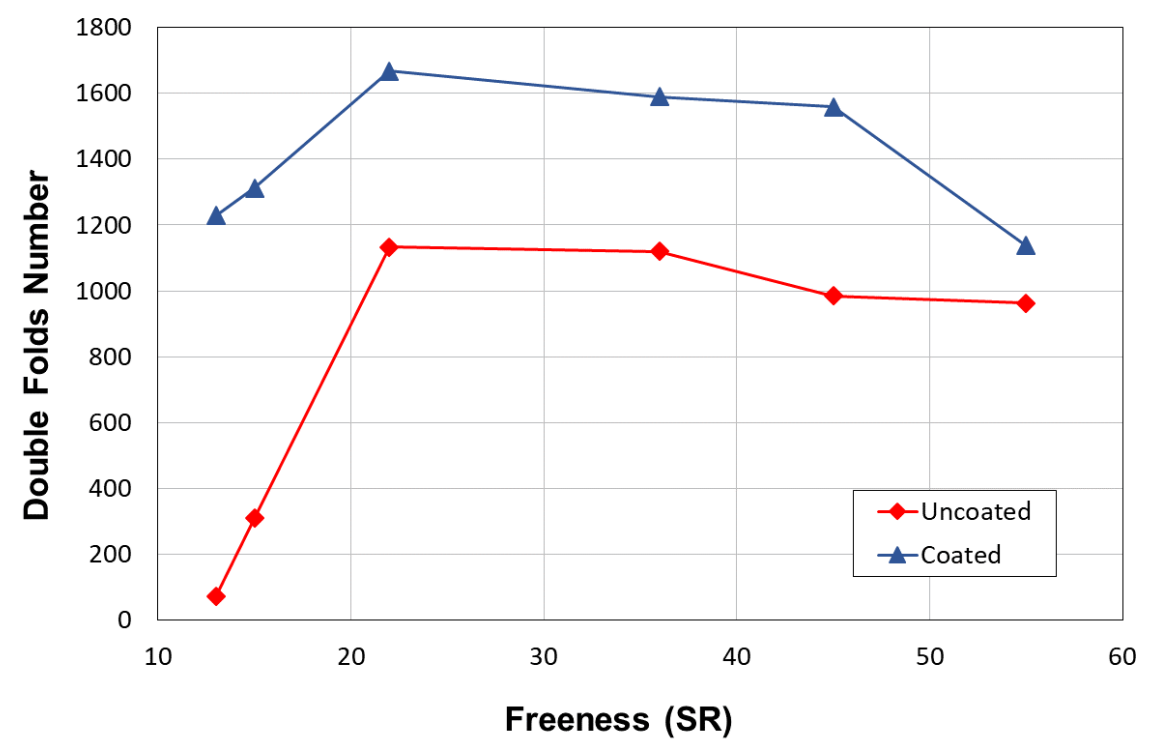

Fig. 9. Comparison of the number of double folds for the laboratory paper samples made from the BSK pulp with different refining degrees for both the uncoated and coated handsheets with cellulose regenerated from NMMO solution

\section{CONCLUSIONS}

1. It was found that a coating consisting of cellulose that was regenerated in situ from an $\mathrm{N}$-methylmorpholine oxide (NMMO) solution increased the apparent density and decreased the paper air permeability as the refining degree increased. For the coated samples, the apparent density of the paper had practically no effect on the final air permeability.

2. The cellulose coating improved the elongation property, resistance to bursting, and the double fold number. An improvement in the tensile strength was also observed, but only for the paper samples that were made from unrefined or lightly refined pulps (up to approximately SR-22).

3. As a result of the cellulose-NMMO coating, the tear resistance of the paper decreased, regardless of the degree of pulp refining. 
4. In general, the improvement in strength properties in paper made from unrefined pulp was most likely because as the degree of pulp refining increased and the air permeability of the paper structure decreased, the cellulose solution had less penetration into the paper structure. As a result, the cellulose-NMMO coating had a limited effect on the papers that were made of heavily refined pulp.

5. The application of the proposed cellulose coating requires a solvent washing operation. This is a disadvantage of this method, so its use as a classic dry strength agent is significantly limited. However, it could be an attractive solution in the case of a need for additional functionalization of a paper structure.

\section{REFERENCES CITED}

Balan, T., Guezennec C., Nicu R., Ciolacu F., and Bobu E. (2015). "Improving barrier and strength properties of paper by multi-layer coating with bio-based additives," Cellulose Chemistry and Technology 49 (7-8), 607-615.

Erdman, A., Kulpiński, P., and Olejnik, K. (2016). “Application of nanocomposite cellulose fibers with luminescent properties to paper functionalization," Cellulose 23(3), 2087-2097. DOI: 10.1007/s10570-016-0943-9

Holik, H. (ed.) (2013). Handbook of Paper and Board, Wiley-VCH, Weinheim, Germany.

Hubbe, M. A., Ferrer, A., Tyagi, P., Yuanyuan, Y., Salas, C., Pal, L., and Rojas, O. J. (2017). "Nanocellulose in thin films, coatings, and plies for packaging applications: A review," BioResources 12(1), 2143-2233. DOI: 10.15376/biores.12.1.2143-2233

ISO 5626 (1993). "Paper and board - Determination of folding endurance (test method)," International Organization for Standardization, Geneva, Switzerland.

ISO 5267-1 (1999). "Pulps - Determination of drainability - Part 1: Schopper-Riegler method," International Organization for Standardization, Geneva, Switzerland.

ISO 5269-2 (2004). "Pulps - Preparation of laboratory sheets for physical testing - Part 2: Rapid-Köthen method," International Organization for Standardization, Geneva, Switzerland.

ISO 187 (1999). "Paper, board and pulps - Standard atmosphere for conditioning and testing and procedure for monitoring the atmosphere and conditioning of samples," International Organization for Standardization, Geneva, Switzerland.

ISO 5263-1 (2004). "Pulps - Laboratory wet disintegration - Part 1: Disintegration of chemical pulps," International Organization for Standardization, Geneva, Switzerland.

ISO 1924-2 (2008). "Paper and board - Determination of tensile properties - Part 2: Constant rate of elongation method $(20 \mathrm{~mm} / \mathrm{min})$," International Organization for Standardization, Geneva, Switzerland.

ISO 534 (2011). "Paper and board - Determination of thickness, density and specific volume," International Organization for Standardization, Geneva, Switzerland.

ISO 1974 (2012). "Paper - Determination of tearing resistance - Elmendorf method," International Organization for Standardization, Geneva, Switzerland.

ISO 8791-2 (2013). "Paper and board - Determination of roughness/smoothness (air leak methods) - Part 2: Bendtsen method," International Organization for Standardization, 
Geneva, Switzerland.

ISO 5636-3 (2013). "Paper and board - Determination of air permeance (medium range) - Part 3: Bendtsen method," International Organization for Standardization, Geneva, Switzerland.

ISO 2758 (2014). "Paper - Determination of bursting strength," International Organization for Standardization, Geneva, Switzerland.

ISO 536 (2019). "Paper and board - Determination of grammage," International Organization for Standardization, Geneva, Switzerland.

Jenkins, S. N. (2009). "The improvement of dry strength by synthetic polymers," in: Applications of Wet End Chemistry, I. Thorn and C. O. Au (eds.), Springer Nature BV, Dordrecht, Netherlands, pp. 91-101.

Krysztof, M., Olejnik, K., Kulpiński, P., Stanisławska, A., and Khadzhynova, S. (2018). "Regenerated cellulose from $N$-methylmorpholine $N$-oxide solutions as a coating agent for paper materials," Cellulose 25(6), 3595-3607. DOI: 10.1007/s10570-0181799-y

Kulpiński, P. (2007). "Cellulose fibers modified by hydrophobic type polymer," Journal of Applied Polymer Science 104(1), 398-409. DOI: 10.1002/app.25150

Li, A., Xu, D., Luo, L., Zhou, Y., Yan, W., Leng, X., Dai, D., Zhou, Y., Ahmad, H., Rao, J., and Fan, M. (2012). "Overview of nanocellulose as additives in paper processing and paper products," Nanotechnology Reviews 10(1), 264-281

Lindström, T., Wågberg, L., and Larsson, T. (2005). "On the nature of joint strength in paper - A review of dry and wet strength resins used in paper manufacturing," in: Proceedings of the $13^{\text {th }}$ Fundamental Research Symposium, Cambridge, United Kingdom, pp. 457-562.

Lofton, M. C., Moore, S. M., Hubbe, M. A., and Lee, S. Y. (2005). "Deposition of polyelectrolyte complexes as a mechanism for developing paper dry-strength development," TAPPI Journal 4(9), 3-8.

Mihara, I., Sakaemura, T., and Yamauchi, T. (2018). "Mechanism of paper strength development by the addition of dry strength resin and its distribution within and around a fiber wall," Nordic Pulp \& Paper Research Journal 23(4), 382-388. DOI: 10.3183/npprj-2008-23-04-p382-388

Morsy, F. A., and El-Sherbiny, S. (2004). "Mechanical properties of coated paper: Influence of coating properties and pigment blends," Journal of Materials Science 39, 7327-7332. DOI: 10.1023/B:JMSC.0000048747.93113.6d

Nechita, P., and Roman, M. (2020). "Review on polysaccharides used in coatings for food packaging papers," Coatings 10(6), 566. DOI: 10.3390/coatings 10060566

Rathi, M, S., and Biermann, C. J. (2000). "Application of polyallylamine as a dry strength agent for paper," TAPPI Journal 83(12).

Rubacha, M. (2006). "Magnetically active composite cellulose fibers," Journal of Applied Polymer Science 101(3), 1529-1534.

Samyn, P., Barhoum, A., Hlund, T., and Dufresne, A. (2018). "Review: Nanoparticles and nanostructured materials in papermaking," J. Mater. Sci. 53(1), 146-184.

Skwierczyńska, M., Runowski, M., Kulpiński, P., and Lis, S. (2019). "Modification of cellulose fibers with inorganic luminescent nanoparticles based on lanthanide(III) ions," Carbohydrate Polymers 206, 742-748. DOI: 10.1016/j.carbpol.2018.11.058

Śmiechowicz, E., Niekraszewicz, B., Kulpiński, P., and Dzitko K. (2018). “Antibacterial composite cellulose fibers modified with silver nanoparticles and nanosilica," Cellulose 25(6), 3499-3517. DOI: 10.1007/s10570-018-1796-1 
TAPPI T 248 sp-00 (2000). "Laboratory beating of pulp (PFI mill method)," TAPPI Press, Atlanta, GA.

Tracton, A. A. (2007). Coatings Technology Handbook, CRC Press, Boca Raton, FL.

Tyagi, P., Lucia, L. A., Hubbe, M. A., and Pal, L. (2019). "Nanocellulose-based multilayer barrier coatings for gas, oil, and grease resistance," Carbohydrate Polymers 206, 281-288. DOI: 10.1016/j.carbpol.2018.10.114

Article submitted: March 24, 2021; Peer review completed: May 31, 2021; Revised version received and accepted: June 6, 2021; Published: June 10, 2021.

DOI: 10.15376/biores.16.3.5376-5389 